\title{
Science Research Writing for Non-Native Speakers of English
}

\section{Hilary Glasman-Deal. \\ London: Imperial College Press, 2009. 257 pages. ISBN: 978-1-84816-310-2.}

It is a well-known fact that ESP/EAP practitioners more than ESL/EFL teachers find that pedagogical materials for their specific ESP course are either unavailable or unsuitable for classroom use. In an attempt to solve the lack of fit between pedagogically "primed" materials (Swales, 2002: 155) that draw on required specialist knowledge and research findings, many ESP and EAP teachers, more often than not, become materials developers and textbook writers. The mismatch has been long identified and different methods, criteria, rating scales and checklists can be found in the literature (for a brief review see Bocanegra-Valle, 2010: 148-149) to help these teachers evaluate published material. In her Science Research Writing for NonNative Speakers of English, Glasman-Deal offers a well-structured and didactic book addressed to non-native speakers of English (NNS) with at least an intermediate level of English who need to write up their research papers for publication in English. As the author herself states, it is a practical, fast doit-yourself manual that aims to provide NNS scientists with both rhetorical and lower-level skills so that their written research complies with the conventions of the scientific community. Given that Glasman-Deal wants to persuade her wide audience of unskilled science writers that "science writing is much easier than it looks" (page vi), she stresses the highly conventional nature of science writing and the relatively reduced amount of grammar and vocabulary they will actually need to learn to empower their texts with the suitable academic flavour.

As an experienced EAP teacher of research writing, Glasman-Deal firmly believes in organizing information and using science writers' reading materials as benchmark samples, or models, to emulate. In the light of this goal, she divides the book in five main units, which correspond to the five main sections of a research paper, namely Introduction, Methodology, Results, Discussions or Conclusion, and Abstract and Title (IMRD model see Swales, 1990). The end materials contain a few recommended further readings as well as four appendices on abbreviations, prefixes, Latin and 
Greek plural forms and a short list of useful verbs. The five units follow the same pattern: several authentic excerpts of every section are given as sample texts; this is followed by a Grammar and Writing Skills section that highlights useful metadiscursive expressions, vocabulary, different ways and gradients of hedging or verb tenses found in every section and, finally, a Key is provided with a sample answer for the student writer to compare. In the Key the author answers frequently asked questions, solves recurrent difficulties encountered by NNS writers and offers a list of useful vocabulary. Many apprentice writers overwhelmed by the complexity of the articles they come across will surely welcome these clear guidelines and, what is more, I would like to suggest the book could even support some native (NS) unskilled science writers. Thus, in this sense we can say the book accomplishes its objective perfectly well.

The readers of the book are asked to collect three or four recent research papers from their specialty beforehand and follow the above described stepby-step procedure to write their article. Glasman-Deal advises that the target articles conforming the homemade corpus should be short, written by a NS, closely related to the student's research and with a clear IMRD structure. However, although it is true that Glasman-Deal's clear and repetitive pattern is very likely conducive to a confident attitude in novice writers, one is left with the doubt that the effort of simplifying science writing and toning down its aura of extreme difficulty is not in fact misrepresenting or impoverishing reality.

To begin with, it might be worth increasing the number of target texts and emphasizing they must have been published "recently", for they are going to serve as benchmark models, and variation - in time, across and within disciplines, across cultures - is an acknowledged fact in genre analysis. For example, Swales and Feak's (2009) book on abstract writing follows a somewhat similar pattern in the sense that they also encourage their readers to prepare a significantly reliable reference collection of abstracts, yet between ten and fifteen is the recommended number of abstracts. Apprentice writers could also be more explicitly "warned against" the unstable and dynamic nature of research articles, even within the same discipline. Different journals within the same discipline have different conventions, and an increased emphasis on the pragmatic and discursive choices underlying different purposes and social aspects of written communication would raise more awareness among readers. When student writers explore their target texts, they should be ready to find that writers 
may well flout the conventional order of moves or use other verb tenses than the recommended tense, for example. Needless to say, that is the price one has to pay to simplify a complex reality - it is difficult not to make somewhat prescriptive generalizations that are highly appreciated by apprentice writers but not completely trustworthy.

Moreover, the questions raised and discussed in the Key are questions or problems that, based on the author's experience with her students, most frequently arise. We do not know the extent to which these questions reflect a somewhat specific profile of students; for instance, Italian, French or Spanish students of English are not likely to find academic verbs like "associate", "consider", "categorise", "maintain" or "precede" as difficult to learn as students from another origin. The latter may need further and more intensive practice in terms of a wider array of diverse tasks like fill-in, assessing, rephrasing, critical thinking, etc.

Finally, we do not know the selection criterion for the useful verbs given at the end of every unit and compiled in a final list: online compilations like Coxhead's (2000) Academic Word List (AWL)? A concordancer? Nation's (2001) classification of frequent words? Personal experience? In line with this, and going one step further, Hyland and Tse (2007) challenge the commonly held assumption of a single core academic vocabulary because of remarkable differences in range, frequency, collocation and meaning. By and large, Glasman-Deal's book partly aligns itself with other EAP and ESP textbooks that, according to scholars from the academic literacy field (Swales \& Feak, 2010: 178), are "over-reliant on textual-formalist approaches (in contrast to those focusing on academic social practices)". Student science writers may feel they still need further practice after working through the textbook but there is no doubt that for them the manual can be a very useful tool toward becoming efficient science writers.

[Review received June 2010]

Reviewed by Marta Aguilar

Universitat Politècnica de Catalunya (Spain)

marta.aguilar@upc.edu

\section{REFERENCES}

Bocanegra-Valle, A. (2010). "Evaluating and designing materials for the ESP classroom" in M. Ruiz-Garrido, J.C. Palmer-Silveira \& I. FortanetGómez (eds.), 141-165.
Coxhead, A. (2000)." A new academic word list". TESOL Quarterly, 34: 213-238.

Hyland, K. \& P. Tse (2007). "Is there an 'Academic 
Vocabulary'?". TESOL Quarterly 41: 235-253.

Nation, I.S.P. (2001). Learning Vocabulary in Another Language. New York: Cambridge University Press.

Ruiz-Garrido, M., J.C. Palmer-Silveira \& I. Fortanet-Gómez (eds.) (2010). English for Professional and Academic Purposes. Amsterdam: Rodopi.

Swales, J. (1990). Genre Analysis. English in Academic and Research Settings. Cambridge: Cambridge University Press.
Swales, J. (2002). "Integrated and fragmented worlds: EAP materials and corpus linguistics" in $\mathrm{J}$. Flowerdew (ed.), Academic Discourse, 150-164. London: Longman.

Swales, J. \& C. Feak (2009). Abstracts and the Writing of Abstracts. Ann Arbor, Ml: University of Michigan Press.

Swales, J. \& C. Feak. (2010). "From text to task: Putting research on abstracts to work" in M. RuizGarrido, J.C. Palmer-Silveira \& I. Fortanet-Gómez (eds.), 167-180. 